\title{
Electrochemical synthesis of oxide nanotubes on Ti6Al7Nb alloy and their interaction with the simulated body fluid
}

\author{
Michal Stẹpień $^{1} \cdot$ Piotr Handzlik $^{1} \cdot$ Krzysztof Fitzner $^{1}$
}

Received: 24 February 2016/Revised: 28 April 2016 / Accepted: 20 May 2016 / Published online: 2 June 2016

(C) The Author(s) 2016. This article is published with open access at Springerlink.com

\begin{abstract}
The aim of the present work was to investigate electrochemical behavior of the Ti6Al7 $\mathrm{Nb}$ alloy in the simulated body fluid (SBF) containing $\mathrm{Ca}^{2+}, \mathrm{HCO}_{3}{ }^{-}$, and $\mathrm{HPO}_{4}{ }^{2}$ - ions. At first, optimal conditions necessary for oxide nanotube formation were determined. The experiments were conducted in the $1 \mathrm{M}\left(\mathrm{NH}_{4}\right)_{2} \mathrm{SO}_{4}$ with $0.5 \mathrm{wt} \% \mathrm{NH}_{4} \mathrm{~F}$ electrolyte at room temperature. Anodization of the alloy samples was carried out under variable external voltage $U$ in the range from 10 to $40 \mathrm{~V}$ at room temperature. Obtained surface morphology was examined by SEM and X-ray techniques. Nanotube diameter was calculated and correlated with the imposed voltage. Having control over the size of nanotubes, samples with the obtained nanostructures of a chosen diameter were immersed into SBF solution with $\mathrm{pH}=7.4$ for a fixed period of time. Then, they were removed from the fluid and subjected to the electrochemical investigation. Corrosion current and corrosion potential were determined, and it was found that the best anticorrosion properties were obtained for heat-treated nanotube layer: $i_{\text {corr }}=39 \mathrm{nA} / \mathrm{cm}^{2}$ and $E_{\text {corr }}=-0.236 \mathrm{~V}$ vs $\mathrm{Ag} / \mathrm{AgCl}$. Finally, the interaction between the oxide surface and the solution was studied using polarization and electrochemical impedance spectroscopy (EIS) techniques.
\end{abstract}

Keywords $\mathrm{Ti} 6 \mathrm{Al} 7 \mathrm{Nb}$ alloy $\cdot$ Oxide nanotubes . Electrochemical measurements $\cdot$ Apatite formation

Michał Stępień

mstepien@agh.edu.pl

1 Faculty of Non-Ferrous Metals, AGH University of Science and Technology, 30 Mickiewicza Avenue, 30-059 Kraków, Poland

\section{Introduction}

Due to aging of our society, there is an increased need for implant manufacturing, and consequently, various materials like stainless steels, $\mathrm{CoCr}$ alloys, and recently, titanium (Ti)based alloys have been tested as biomaterials in orthopedic and dental applications [1]. Since these materials must be biocompatible, i.e., non-toxic and they should not cause any inflammatory or allergic reactions [2], titanium alloys seem to be the best candidate for the majority of these applications.

It has been already demonstrated that titanium and Ti-based alloys are highly corrosion resistant in different environments [3] including body fluids [4]. In most aqueous solutions, they form a stable passive oxide layer, which is responsible for this particular property. Titanium itself, however, has high bulk modulus ( 100 GPa) which makes this metal not compatible with mechanical properties of the bones. Therefore, other nontoxic elements like $\mathrm{Ta}, \mathrm{Zr}, \mathrm{Nb}$, and $\mathrm{Pd}$ were considered as the components of engineered biomedical alloys which exhibit reduced bulk modulus. First Ti alloy implemented as a biomaterial was Ti6A14V alloy originally developed for aerospace applications. It was soon discovered that a multicomponent alloy Ti35Nb7Zr5Ta has bulk modulus as low as $55 \mathrm{GPa}$, which is close to that of the bone (30 GPa) [5]. However, the possibility of adjusting mechanical properties by varying alloy composition raised the question of their electrochemical behavior, since it may not be obvious whether passive layer of $\mathrm{TiO}_{2}$ formed on the Ti surface remains unchanged after alloying.

To answer that question, a corrosion behavior of Ti alloys in artificial bioliquids was investigated in a number of studies. Assis and Costa [6] compared electrochemical behavior of Ti13Nb13Zr, Ti6A14V, and Ti6A17Nb alloys in Hank's solution and found that their behavior is very similar. They used long-term immersion tests and employed both, electrochemical impedance spectroscopy (EIS) and polarization methods. 
Experiments showed that these alloys exhibit very high corrosion resistance in this electrolyte, which is maintained by developed dense, passive oxide layer. Popa et al. [7] correlated microstructure and corrosion behavior of Ti6Al7Nb alloy in Ringer and Ringer-Brown solutions with different $\mathrm{pH}$ : 2.49, 6.9, and 8.9. All samples showed spontaneous passivity with passive current densities lower than pure Ti. Looking for vanadium-free alloys, Robin et al. investigated corrosion behavior of a series of Ti13 $\mathrm{Nb} 13 \mathrm{Zr}$ alloys with variable $\mathrm{Nb}$ content in Ringer solution [8]. Comparing the results of electrochemical studies with those obtained for Ti and Ti6A14V alloys, they found that the resistance of a passivating film is higher for Ti13 $\mathrm{Nb} 13 \mathrm{Zr}$ alloy, which indicates higher corrosion resistance. In the similar study, Al-Mobarak et al. [9] compared corrosion behavior of titanium alloy Ti6 A17 Nb with that determined for Ti6A14V alloy. For tests in Hank's solution, they found that the alloy with niobium has higher corrosion resistance. They concluded that Ti6Al7Nb alloy can be used instead of the alloy containing vanadium, if the problems connected with vanadium release have to be avoided.

The influence of a microstructure on corrosion characteristics of Ti13 $\mathrm{Nb13Zr}$ alloy in Ringer solution was investigated by Cvijovic-Alagic et al. [10]. They found that this alloy exhibits spontaneous passivity; however, the protective layer is formed more rapidly on Ti6Al4V alloy. The corrosion resistance of Ti13Nb13Zr alloy is very similar to that of martensitic Ti6A14V alloy. Simka et al. [11] pointed out that surface treatment by electrolytic polishing influences corrosion resistance. They studied this influence on Ti13Nb13Zr alloy and found that after electropolishing, the corrosion resistance increased significantly. Apparently smooth surface stimulated oxide layer formation. As far as corrosion resistance is concerned, the addition of noble metals to Ti may also have beneficial effect. We found that Ti-Pd alloy in phosphate-buffered saline (PBS) solution with $\mathrm{H}_{2} \mathrm{O}_{2}$ addition simulating the inflammatory state has better corrosion resistance than pure $\mathrm{Ti}$ [12].

The formation of the oxide layer on the alloy surface is not enough to conclude whether this material will bond to the living bone. It is known that biological integration requires good bone formability. One may suggest that bioactivity of the material can be predicted from the apatite formation on its surface in a simulated body fluid (SBF) [13]. It was also recently demonstrated that to assure good osseo-integration, $\mathrm{TiO}_{2}$ nanotubes formed on the Ti surface enhance hydroxyapatite formation, which in turn bonds to a living bone [14, 15]. Tsuchiya et al. [16] showed that self-organized tubular oxide layer can be formed on TiAl alloys. Adhesion of hydroxyapatite coating on Ti6A14V implant was extensively analyzed by Mohsendi et al. [17]. They found that using an interfacial layer made of $\mathrm{TiO}_{2}$ can enhance the bonding strength. Consequently, the aim of the present study is twofold: -first, to find proper conditions for the formation of the tubular self-organized oxide layer on the Ti6Al7Nb alloy surface, and to determine its corrosion behavior in SBF solution; and

-second, to check if this oxide layer assures enhancement of apatite formation on its surface.

\section{Experimental}

Titanium foils ( $99.7 \%$ purity $1.0-\mathrm{mm}$ thick, Alfa Aesar) and Ti6Al7Nb alloy (ISO-5832-11, extruded rod $22 \mathrm{~mm}$, Bibus Metals) were cut into slices on the cutting wheel. They were mechanically polished on cloth to $1 \mu \mathrm{m}$ and ultrasonically cleaned using deionized water and acetone. The samples having area of $1.13 \mathrm{~cm}^{2}$ were anodized in electrolyte containing $1 \mathrm{M}\left(\mathrm{NH}_{4}\right)_{2} \mathrm{SO}_{4}(\mathrm{POCH})$ and $0.5 \mathrm{wt} \% \mathrm{NH}_{4} \mathrm{~F}(\mathrm{POCH})$ [18]. During all anodization processes, the electrolyte was stirred using magnetic stirrer. Anodization was carried out at room temperature in two-electrode electrochemical cell with platinum sheet as counter electrode (CE) and Ti6Al7Nb alloy as a working electrode (WE). As a power supply, programmable DC power supply Agilent N5751A with digital multimeter Keithley 2100 was used. This procedure was similar to that reported in our previous paper [19] on the synthesis of $\mathrm{ZrO}_{2}$ nanotubes. After anodization, samples were rinsed with deionized water and ultrasonically cleaned and dried in air stream. Part of the samples was annealed in air at $200{ }^{\circ} \mathrm{C}$ for $8 \mathrm{~h}$ to remove residual traces of fluorine and moisture.

Polarization, open circuit potential (OCP), and EIS measurements were performed using an AUTOLAB Potentiostat, PGSTAT $128 \mathrm{~N}$ with FRA2 (frequency response analyzer) module controlled by NOVA 1.8 electrochemical interface. Usually, each experiment was repeated three times. Threeelectrode electrochemical cell with $\mathrm{Ag} / \mathrm{AgCl}$ as reference electrode (RE) was used (Fig. 1). The working electrodes consisted finally of disks with active surface area of $0.50 \mathrm{~cm}^{2}$ isolated by O-ring. All the electrochemical investigations were carried out in SBF solution at $\mathrm{pH} 7.4$, prepared according to the recipe given by Kokubo and Takadama [13]. It contains the mixture of $\mathrm{NaCl}(8.035 \mathrm{~g}), \mathrm{KCl}(0.225 \mathrm{~g})$, $\mathrm{NaHCO}_{3}(0.355 \mathrm{~g}), \mathrm{K}_{2} \mathrm{HPO}_{4} \cdot 3 \mathrm{H}_{2} \mathrm{O}(0.231 \mathrm{~g}), \mathrm{MgCl}_{2} \cdot 6 \mathrm{H}_{2} \mathrm{O}$ (0.311 g), $39 \mathrm{ml} 1 \mathrm{M} \mathrm{HCl}, \mathrm{CaCl}_{2}(0.292 \mathrm{~g}), \mathrm{Na}_{2} \mathrm{SO}_{4}(0.072 \mathrm{~g})$, and tris-hydroxymethyl aminomethane $\left(\left(\mathrm{HOCH}_{2}\right)_{3} \mathrm{CNH}_{2}\right)$ $(6.118 \mathrm{~g})$ dissolved in $1000 \mathrm{ml}$ demineralized water. The electrolyte was maintained at constant temperature $36.6 \pm 0.2{ }^{\circ} \mathrm{C}$ and not stirred during all experiments and measurements. All electrolytes were prepared using analytical purity grade chemicals and deionized water. Open circuit potential was measured for $12 \mathrm{~h}$ with sampling rate $10 \mathrm{~s}$.

The linear polarization method was used to determine the corrosion current densities $\left(i_{\text {corr }}\right)$ and corrosion potentials $\left(E_{\text {corr }}\right)$. Polarization potential $\pm 500 \mathrm{mV}$ vs. OCP was applied after 24-h sample immersion, (in order to obtain stabilization of 


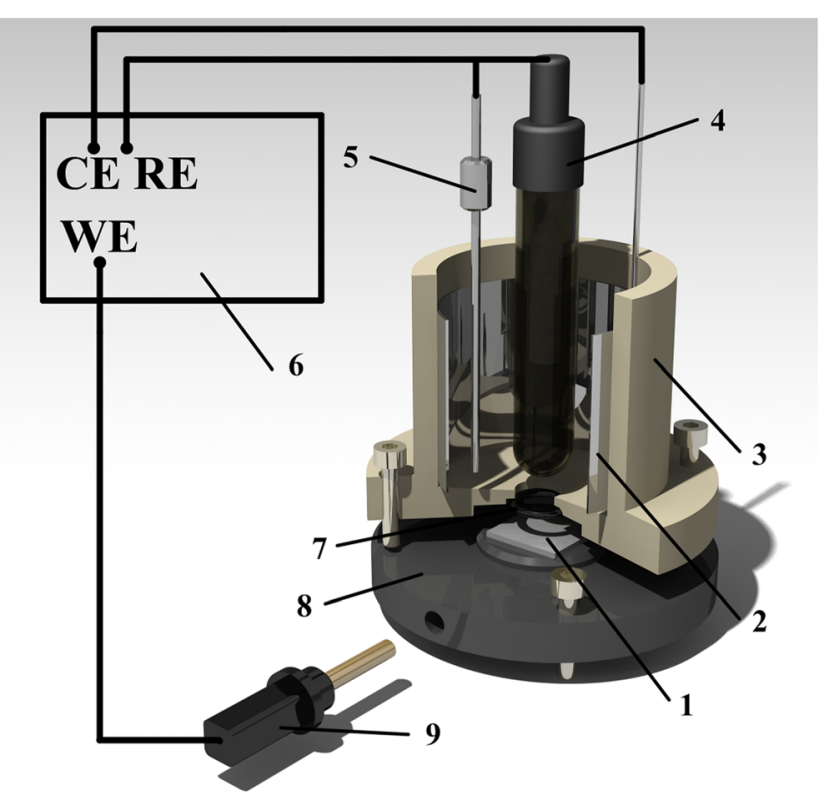

1 - Working electrode

2 - Counter electrode - Pt sheet

3 - PTFE cell body

4 - Reference electrode - Ag/AgCl

5 - Pt rod in series with capacitor

6 - Potentiostat

7 - O-ring

8 - SS ANSI 316Ti base

9 - Connector

Fig. 1 Three-electrode electrochemical cell used in the experiments

the potential and wetting of the tubes surface by SBF) at the scan rate of $1 \mathrm{mV} / \mathrm{s}$. Both, $E_{\text {corr }}$ and $i_{\text {corr }}$, were calculated using NOVA 1.8 software. The parameter which determined the approach towards stationary potential was the rate of its change recorded with time. For a rate smaller than $0.001 \mathrm{mV} / \mathrm{s}$, it was assumed that stationary potential has been reached.

The electrochemical impedance test at OCP after $24 \mathrm{~h}$ of immersion was performed, and experiments were repeated every 7 days up to end of immersion test. EIS spectra were acquired in the frequency range of $100 \mathrm{kHz}-0.01 \mathrm{~Hz}$ for 10 points per decade using single sine wave of $10-\mathrm{mV}$ peak to peak amplitude. The results were analyzed with the fitting program ZVIEW version 2.0.

The immersion test was conducted in SBF at human body temperature of $36.6^{\circ} \mathrm{C}$ for 28 days. SBF was exchanged every $24 \mathrm{~h}$ by pouring out the solution and pouring in the fresh one. After the immersion test was completed, the sample was gently rinsed with demineralized water and dried in air stream.

The morphology of the anodized sample was investigated by using scanning electron microscope (SEM) (Hitachi SU-70). Structural analysis of a nanotube layer was carried out with an X-ray diffractometer (Rigaku MiniFlex II) using monochromatic $\mathrm{Cu} \mathrm{K} \alpha$ radiation $(0.15416 \mathrm{~nm})$. All samples were studied by point analyses using EDS analysis (Thermo Scientific) attached to the SEM to obtain chemical composition of the nanotubular layer. The X-ray photoelectron spectroscopy (XPS) spectra were registered with the use of photoelectron spectrometer Versa Probe II (PHI Electronics). To check compatibility of the initial sample composition with the equilibrium phase diagram, an isothermal section of Ti-Al-Nb system was calculated at room temperature with ThermoCalc software.

\section{Results}

\section{Ti6Al7Nb alloy phase composition}

Investigation of the alloy samples by SEM back-scattered electrons (BSE) and X-ray diffractometry showed that the alloy used in our experiments is composed of two phases: a hexagonal close-packed (hcp) $\alpha$ phase and a body-centered cubic (bcc) $\beta$ phase. This is demonstrated in Fig. 2a-e. These results are compatible with the similar alloy analysis reported by Sitting et al. [20].

A comparison of this result with the equilibrium phase diagram calculated for $\mathrm{Ti}-\mathrm{Al}-\mathrm{Nb}$ system at room temperature (Fig. 3) indicates that this alloy is in fact in nonequilibrium state. At this composition ( $\left.X_{\mathrm{Ti}}=0.86, X_{\mathrm{Al}}=0.10\right)$, and at room temperature, alfa hcp phase should be in equilibrium with the ternary $\mathrm{O}_{2}-\mathrm{Ti}_{2} \mathrm{NbAl}$ phase. More detailed analysis of the phase diagram shows that this ternary phase is formed in eutectoid reaction from bcc beta phase at $1260 \mathrm{~K}$. It seems that identified in the sample beta phase is the result of the alloy preparation process, in which ternary phase did not manage to precipitate yet. Pandat Software [21] and the data optimized by Witusiewicz et al. [22] were used to complete these calculations.

\section{Nanotubes formation}

After preparation of the alloy samples, they were anodized to form oxide nanotube layer on the alloy surface.

Anodization of the samples was carried out in the voltage range from 10 to $40 \mathrm{~V}$, and nanotubes morphology was obtained in the range from 10 to $35 \mathrm{~V}$.

The process of nanotube formation on titanium-rich alloys has been already described in the literature by Macak et al. [23], Crawford et al. [24], Roy et al. [25], and Rafieerad et al. [26]. It consists of several steps which can be described as follows:

1. field-assisted dissolution of titanium takes place due to the very high electric field across the electrode:

$$
\mathrm{Ti} \rightarrow \mathrm{Ti}^{4+}+4 \mathrm{e}
$$

$$
\mathrm{Ti}^{4+}+\mathrm{H}_{2} \mathrm{O} \rightarrow \mathrm{TiO}_{2}+4 \mathrm{H}^{+}
$$


Fig. 2 Investigation of the Ti6Al7Nb alloy: a SEM-BSE image, b XRD spectrum, c EDS spectrum for $\alpha$ phase, $\mathbf{d}$ EDS spectrum for $\beta$ phase, and e alloy composition based on EDS analysis results
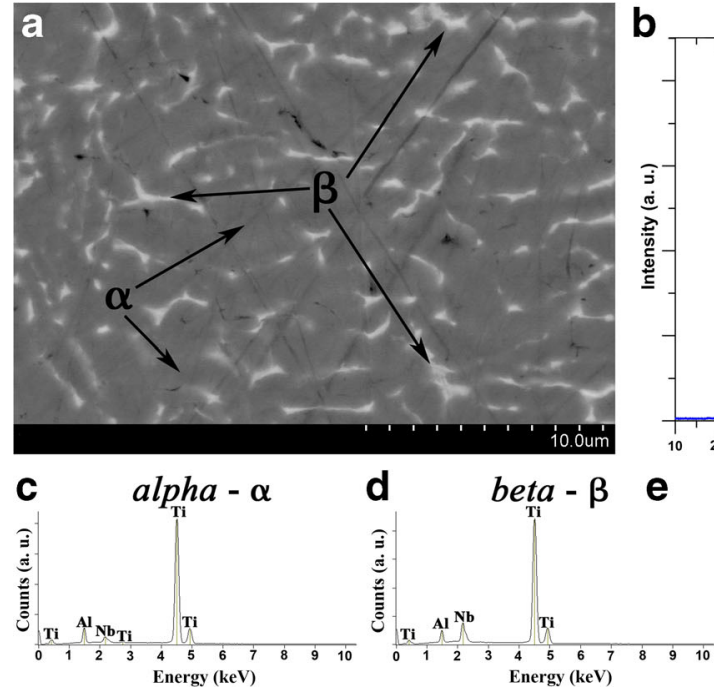

Energy (keV) b

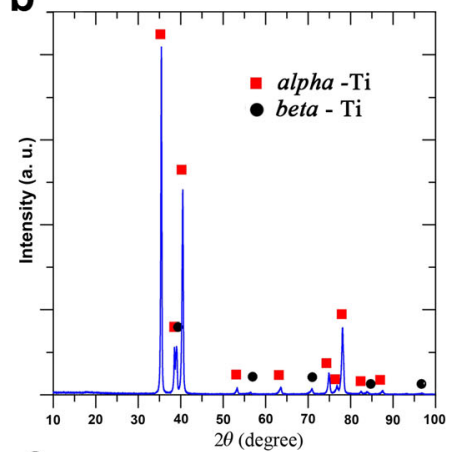

Alloy phase composition (wt \%)

$\mathrm{Ti} \quad \mathrm{Al} \quad \mathrm{Nb}$

$\begin{array}{llll}\alpha & 89.2 & 5.9 & 4.9\end{array}$

$\begin{array}{llll}\beta & 82.0 & 4.1 & 13.9\end{array}$
During this stage, $\mathrm{TiO}_{2}$ is formed at the metal/electrolyte interface.

2. in the fluoride ions containing acidic electrolyte, dissolution of the oxide layer takes place. As field-assisted growth slows down due to increasing oxide thickness, competing chemical reaction proceeds:

$$
\mathrm{TiO}_{2}+6 \mathrm{~F}^{-}+4 \mathrm{H}^{+} \rightarrow\left[\mathrm{TiF}_{6}\right]^{-}+2 \mathrm{H}_{2} \mathrm{O}
$$

This localized dissolution is responsible for pores formation.

3. the transfer of $\mathrm{Ti}^{4+}$ ions from metal to the oxide surface is accompanied by the transfer of $\mathrm{O}^{2-}$ and $\mathrm{F}^{-}$ions to the metal/oxide interface. It was shown by Habazaki et al. [27] that the fluoride ions migrate inwards at a rate twice that of $\mathrm{O}^{2-}$ ions. They accumulate at the interface between

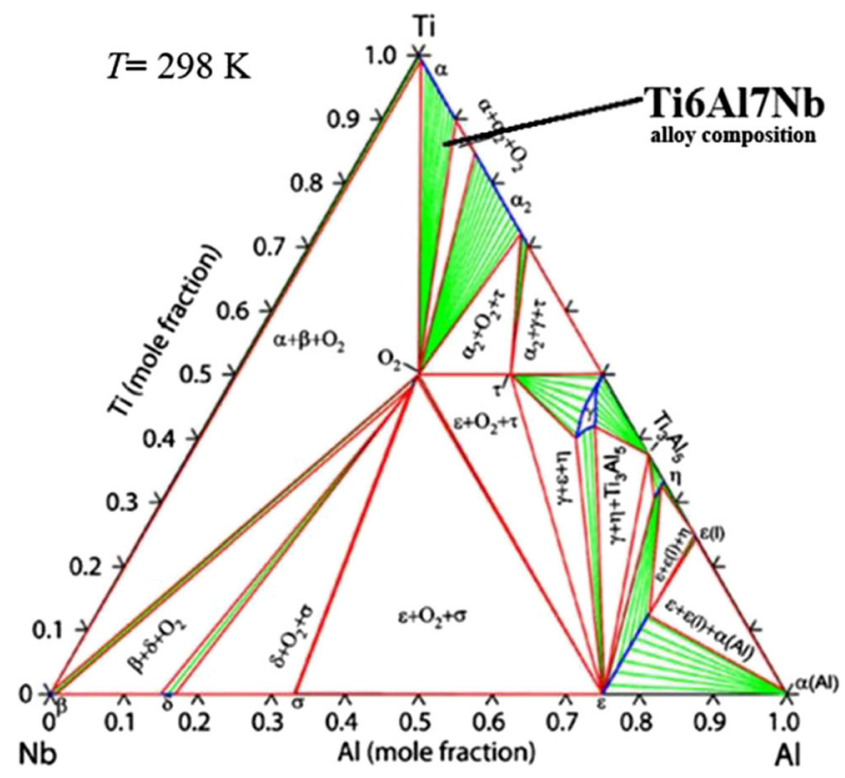

Fig. 3 Calculated Ti-Al-Nb phase diagram the alloy and anodic oxide where a thin $\mathrm{TiF}_{4}$ layer is formed between the metal and the oxide as well as on the outer sides of the pores.

4. Volume expansion of the oxide and fluoride may result in the plastic flow, which pushes the fluoride-rich layer upwards. Such a model was suggested by Garcia-Vergara et al. [28]. It is the beginning of the tube formation. When rates of oxide formation and oxide dissolution became equal, the steady state is reached inside each pore resulting in steady tube growth.

Figure 4 shows SEM top view of the nanotube layer formed during the experiments after $2 \mathrm{~h}$ of anodization at room temperature

In this voltage range, the outer tube diameter varied approximately in the range from 50 to $180 \mathrm{~nm}$, while the inner tube diameter varied in the range from 20 to $100 \mathrm{~nm}$. In both cases, the diameter increases approximately linearly with an increasing anodization voltage, but at a different rate. These results of diameter measurements are shown in Fig. 5.

We found that the increase of the diameter can be described with the following equations:

$d_{\text {inner }}=3.75 \times U(V)-14.33(\mathrm{~nm})$

$d_{\text {outer }}=5.55 \times U(V)-12.91(\mathrm{~nm})$

Another characteristic feature visible after anodization is the oxide surface morphology which shows the patches of another oxide formed on the alloy surface. The comparison of this result with the microstructure of the alloy before anodization suggests that another oxide has grown on $\beta$ phase grains (Fig. 6a, b) enriched in $\mathrm{Nb}$.

XPS spectra of as-synthesized nanotube array and chemical composition show (Fig. 6c ) that the oxide is composed predominantly of $\mathrm{TiO}_{2}$, but $\mathrm{Al}$ and $\mathrm{Nb}$ oxides are also present. The results indicate that $\mathrm{Ti}$ is present in the $\mathrm{Ti}^{4+}$ state. The Ti 
Fig. 4 SEM top views of $\mathrm{TiO}_{2}$ nanotube layers formed after $2 \mathrm{~h}$ of anodization
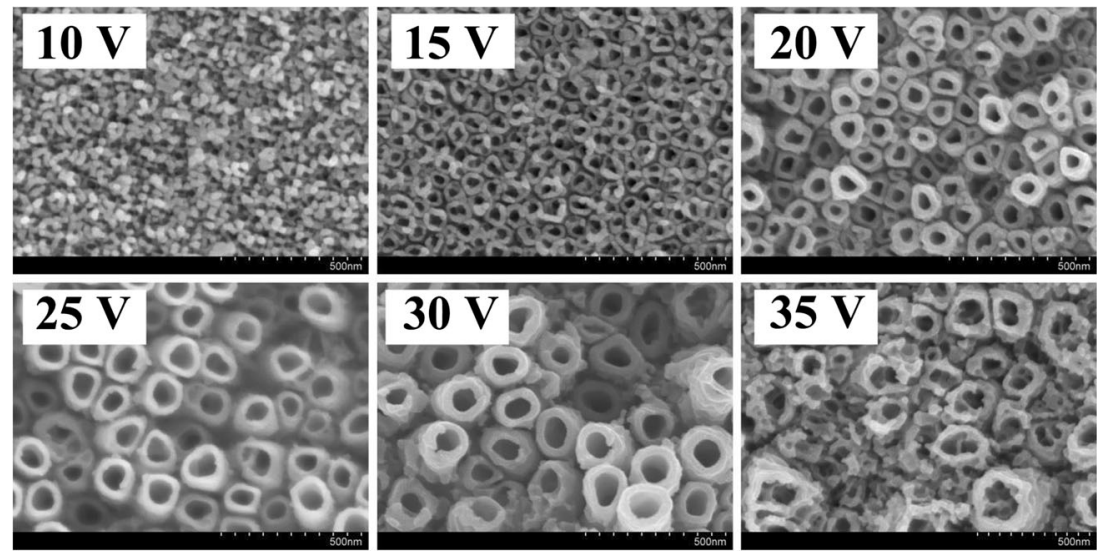

$2 \mathrm{p}$ doublet structure with $2 \mathrm{p}_{3 / 2}$ peak centered at $458.5 \mathrm{eV}$ confirms the presence of $\mathrm{TiO}_{2}$ [29].

\section{OCP measurements}

One of the ways to study the corrosion behavior of the materials is to check the open circuit potential (OCP) as a function of time. OCP variation versus time in SBF solution was recorded for bare Ti and bare Ti6Al7Nb and for Ti6Al7Nb samples covered with the oxide nanotube layers without heat treatment (Ti6Al7Nb-NT) and after heat treatment (Ti6Al7NbNT-HT). Potential evolution with time was monitored for $12 \mathrm{~h}$. The results of these measurements are shown in Fig. 7.

It is seen that the potential of untreated samples ( $\mathrm{Ti}$ and Ti6Al7Nb) changed in positive direction approaching after $12 \mathrm{~h}$ the value of $-0.116 \mathrm{~V}$ vs. $\mathrm{Ag} / \mathrm{AgCl}$ for $\mathrm{Ti}$, and $-0.040 \mathrm{~V}$ vs. $\mathrm{Ag} / \mathrm{AgCl}$ for Ti6 $\mathrm{Al} 7 \mathrm{Nb}$ alloy. In this case, the shift of the potential towards the nobler values reveals that on

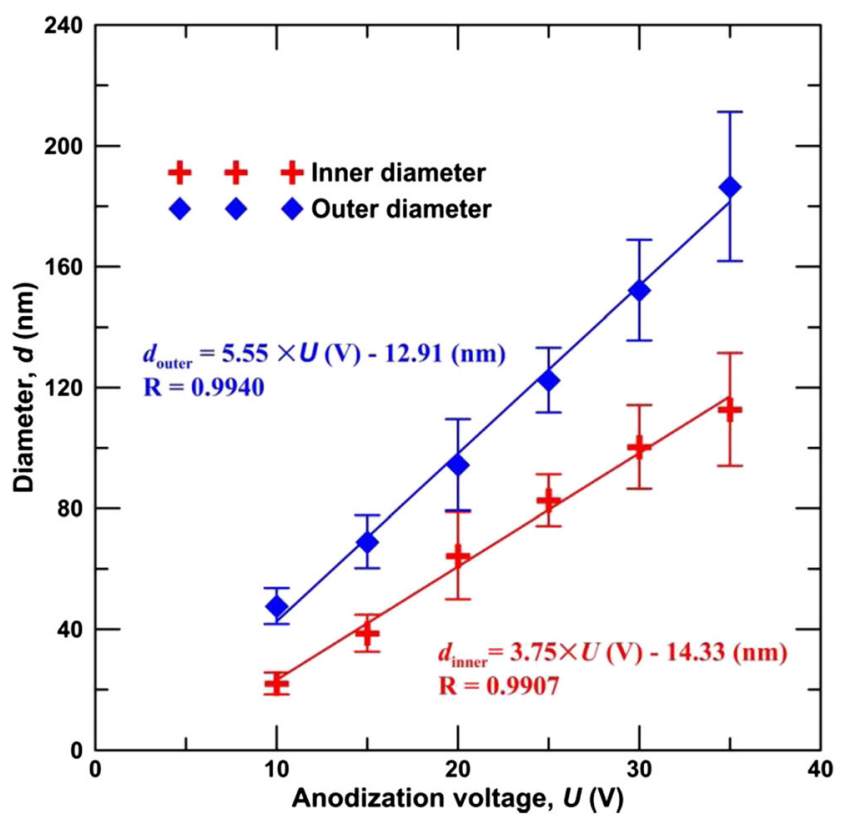

Fig. 5 The change of nanotube diameter with anodization voltage the surface of metals, a protective oxide film is being formed. It is known that after immersion into fluoride-free electrolyte, compact oxide layer is formed on the surface. To produce oxide nanotubes layer, the samples were anodized in fluoride-containing electrolyte at one potential of $30 \mathrm{~V}$. This potential was chosen for further study since; on one hand, well-developed round shape of nanotubes is formed between 20 and $30 \mathrm{~V}$. On the other hand, bigger diameter assures better electrolyte penetration. It can be seen in the same Fig. 7 that for porous nanotube surface on Ti6Al7Nb-NT obtained by anodization process at $30 \mathrm{~V}$, the potential decreased slightly from $0.057 \mathrm{~V}$ vs. $\mathrm{Ag} / \mathrm{AgCl}$ after immersion to $-0.007 \mathrm{~V}$ vs. $\mathrm{Ag} / \mathrm{AgCl}$ at the end of this experiment. This trend of potential falling can be attributed either to progressive surface wettability inside the tubes or reaction with the residue of fluoride. Samples of Ti6Al7Nb-NT-HT after heat treatment exhibit almost constant potential vs. $\mathrm{Ag} / \mathrm{AgCl}$ on $0.000 \mathrm{~V}$ level. For all the investigated electrodes, the potential changes (rapidly for samples without any treatment) during the first $30 \mathrm{~min}$ and then, is slowly approaching constant value. The results demonstrate that the alloy covered with oxide nanotubes exhibits the most positive OCP potential in the environment under investigation. This may mean that NT and NT-HT covers improve corrosion resistance of Ti6 $\mathrm{Al} 7 \mathrm{Nb}$ alloy, as compared with pure titanium and bare alloy.

\section{Polarization measurements}

Recorded polarization curves are shown in Fig. 8. Determined corrosion currents and corrosion potentials based on Tafel plots are gathered for all the samples in Table 1. The results show that the poorest corrosion resistance exhibits the alloy covered with as-synthesized nanotubes without heat treatment. It is known that except for $\mathrm{Zr}$, porous amorphous oxide layers are formed during anodization of $\mathrm{Ti}, \mathrm{Nb}, \mathrm{Ta}$, and $\mathrm{W}$ [30]. Similar amorphous structure was recently observed after anodization of Ti6Al7 Nb alloy [26]. However, in case of the alloy, Ghicov et al. [31] demonstrated that the presence of another oxide in the oxide matrix enhances the stability of 
Fig. 6 Alloy surface morphology before (a) and after anodization (b). White fields correspond to $\beta$ phase enriched in Nb. c XPS spectra and chemical composition of as-synthesized nanotube array
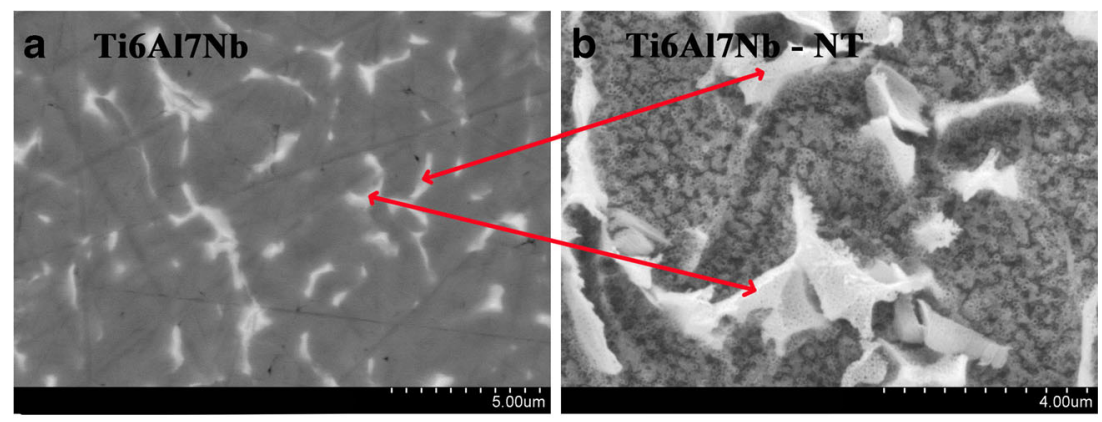

C

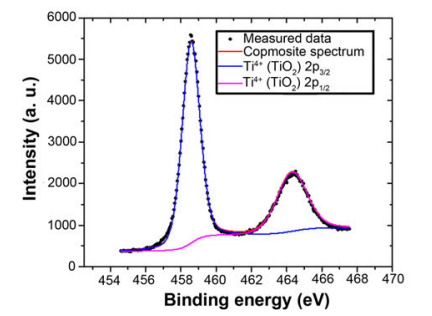

Atomic concentration (\%)

\begin{tabular}{|c|c|c|c|c|c|c|}
\hline C & $\mathrm{O}$ & $\mathrm{Al}$ & $F$ & $\mathrm{Si}$ & $\mathrm{Ti}$ & $\mathrm{Nb}$ \\
\hline 27. & 49.0 & 2.4 & 3.2 & 1.8 & 15.4 & 1.1 \\
\hline
\end{tabular}

the crystallite phase. In our case, X-ray patterns obtained for as-anodized samples revealed also an amorphous oxide, which transformed into anatase at about $450{ }^{\circ} \mathrm{C}$. Thus, our polarization experiments indicate that the formation of amorphous oxide nanotubes on the investigated alloy increases the corrosion current.

Samples of $\mathrm{Ti}$, bare alloy, and alloy with heat treatment nanotubes show similar corrosion potentials and also similar corrosion current densities (Table 1). However, the lowest corrosion current density was recorded for the alloy with heat-treated nanotubes. It demonstrates the best corrosion resistance. The polarization curves obtained for the alloy covered with nanotubes after heat treatment at $200{ }^{\circ} \mathrm{C}$ show positive shift as compared to pure $\mathrm{Ti}$ indicating better corrosion resistance. However, the alloy samples covered with nanotube layer without the heat treatment, as it was already mentioned, indicate poor corrosion resistance. It may mean that porous oxide layer does not shield the transport of electrons and ions between the metallic substrate and the solution.

These results are similar with the results obtained for $\mathrm{Zr}$ by Wang and Luo [32]. They pointed out that the nanotubes

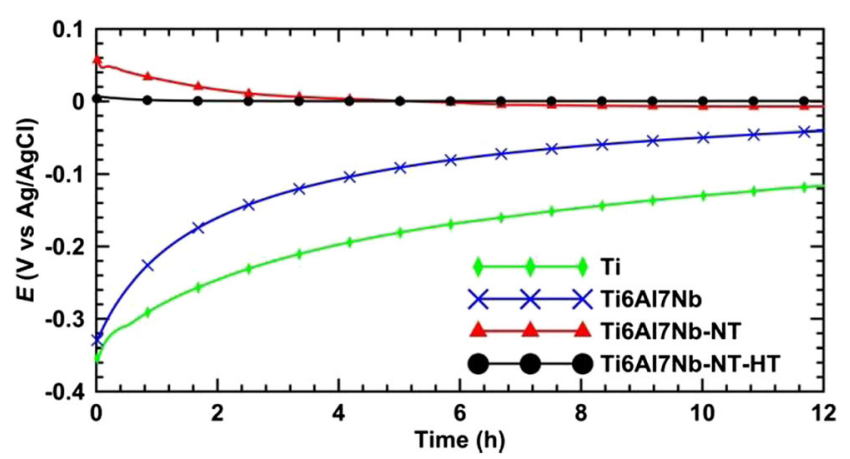

Fig. 7 OCP vs. time plots obtained in SBF solution during 12-h immersion increase oxide surface area significantly and provide more channels for the electrolyte to reach the barrier layer. It results in a significant decrease of anticorrosion properties of the obtained oxide film and explains high value of the corrosion current for the alloy sample after anodization.

The fact that the heat treatment changes significantly the corrosion behavior of oxide nanotubes must have something to do with changes brought about by the annealing. It is known that due to the nanotube formation in fluoridecontaining electrolyte, as-prepared oxides show the presence of fluorine. There are two ways in which fluoride ions can be trapped in the oxide matrix. One way results from the mechanism of nanotube formation. Due to faster $\mathrm{F}^{-}$ion migration through the oxide [27], very thin $\mathrm{TiF}_{4}$ fluoride layer is formed at the metal/oxide interface. This layer can be later removed by dissolving in water-containing electrolyte. This process was observed by Fang et al. [33] who studied the nanotube evolution on $\mathrm{Zr}$ with time. They demonstrated that the compact layer rich in fluorine is formed between the metal and upper tubular layer after $1 \mathrm{~h}$ of anodization, and then, it disappears after $3 \mathrm{~h}$. This experiment shows that the outer layer of

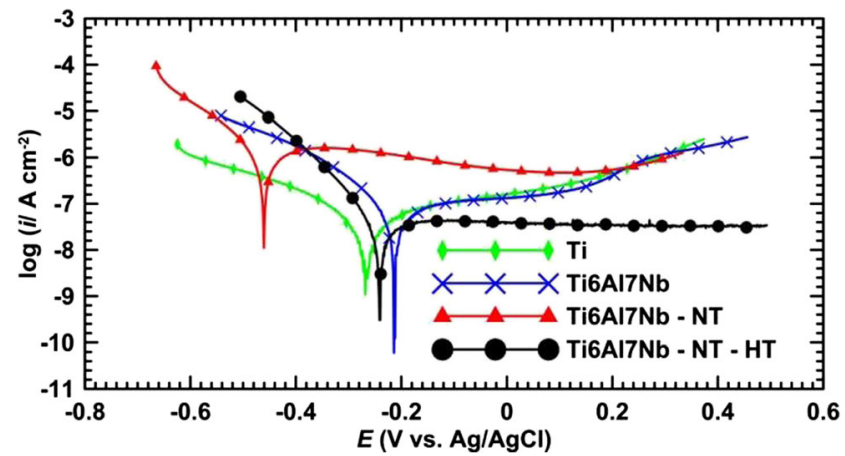

Fig. 8 Polarization curves recorded for Ti, Ti6Al7Nb, Ti6Al7Nb-NT, and Ti6al7Nb-NT-HT 
Table 1 Corrosion current and corrosion potentials obtained from polarization test

\begin{tabular}{lll}
\hline Sample & $i_{\text {corr }}\left(\mathrm{nA} \mathrm{cm}^{-2}\right)$ & $E_{\text {corr }}(\mathrm{V}$ vs Ag/AgCl $)$ \\
\hline Ti & $69 \pm 4$ & $-0.262 \pm 0.030$ \\
Ti6Al7Nb & $91 \pm 14$ & $-0.212 \pm 0.021$ \\
Ti6A17Nb-NT & $968 \pm 58$ & $-0.497 \pm 0.049$ \\
Ti6Al7Nb-NT-HT & $39 \pm 4$ & $-0.236 \pm 0.020$ \\
\hline
\end{tabular}

nanotubes is fluoride-rich and it can be dissolved in the electrolyte. During annealing, it can be removed with the moisture as HF [34]. Another way is possible substitution of oxygen atoms with fluorine atoms in the bulk oxide. The presence of $\mathrm{F}$
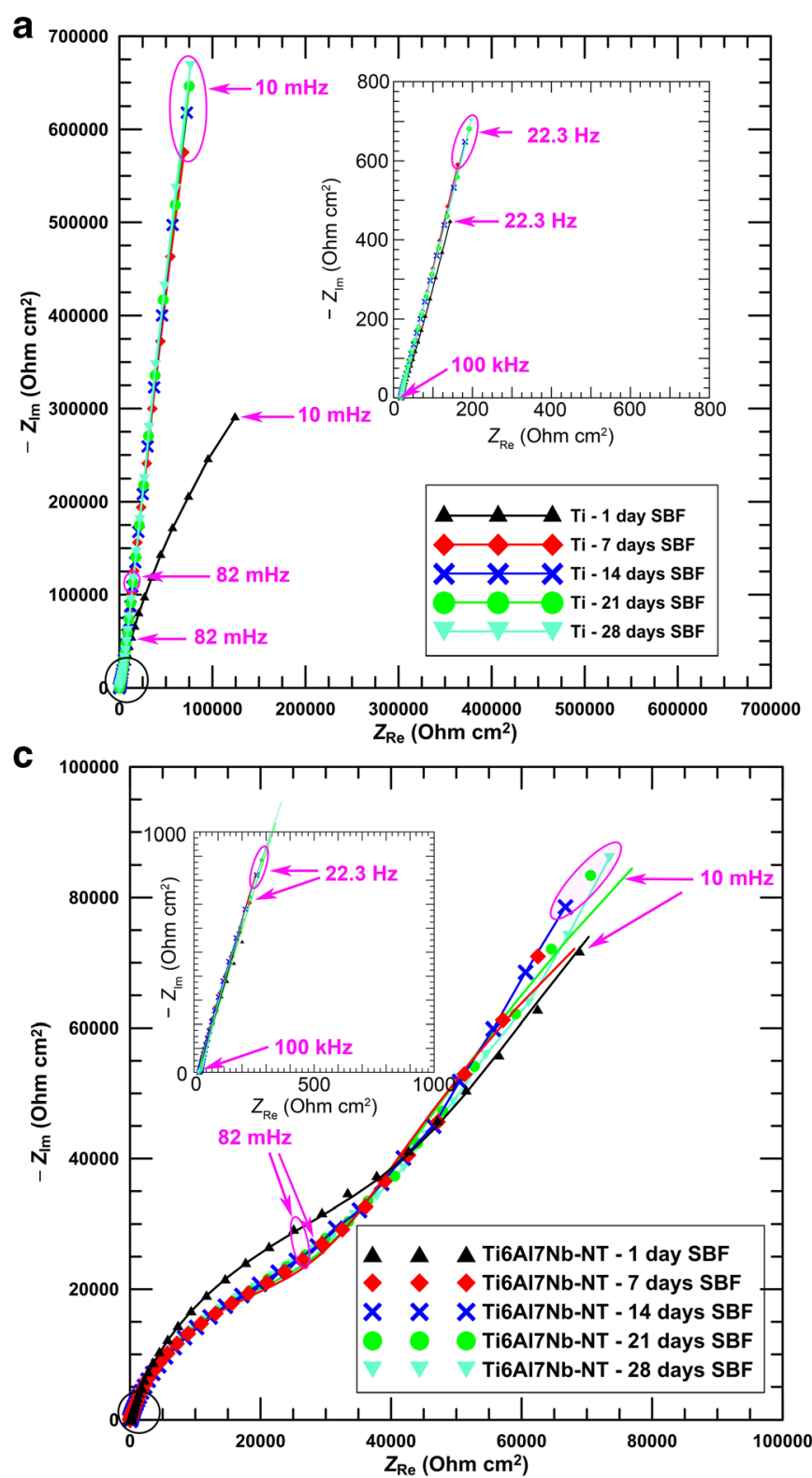

on oxygen sites generates (in Kroger-Vink notation) excess electrons:

$\mathrm{O}_{\mathrm{O}}+\mathrm{F}=\frac{1}{2} \mathrm{O}_{2}+\mathrm{F}_{\mathrm{o}}+e^{\prime}$

enhancing n-type conductivity. Annealing in the oxygencontaining atmosphere removes both $\mathrm{F}$ and electrons decreasing the conductivity. This effect was observed by Vacandio et al. [34] during investigations of electrical properties of zirconia nanotubes before and after annealing.

Independently of the way of the fluoride ion removal, there can be a parallel process responsible for the enhancement of anticorrosion properties of NT-HT alloy. In our case, heat
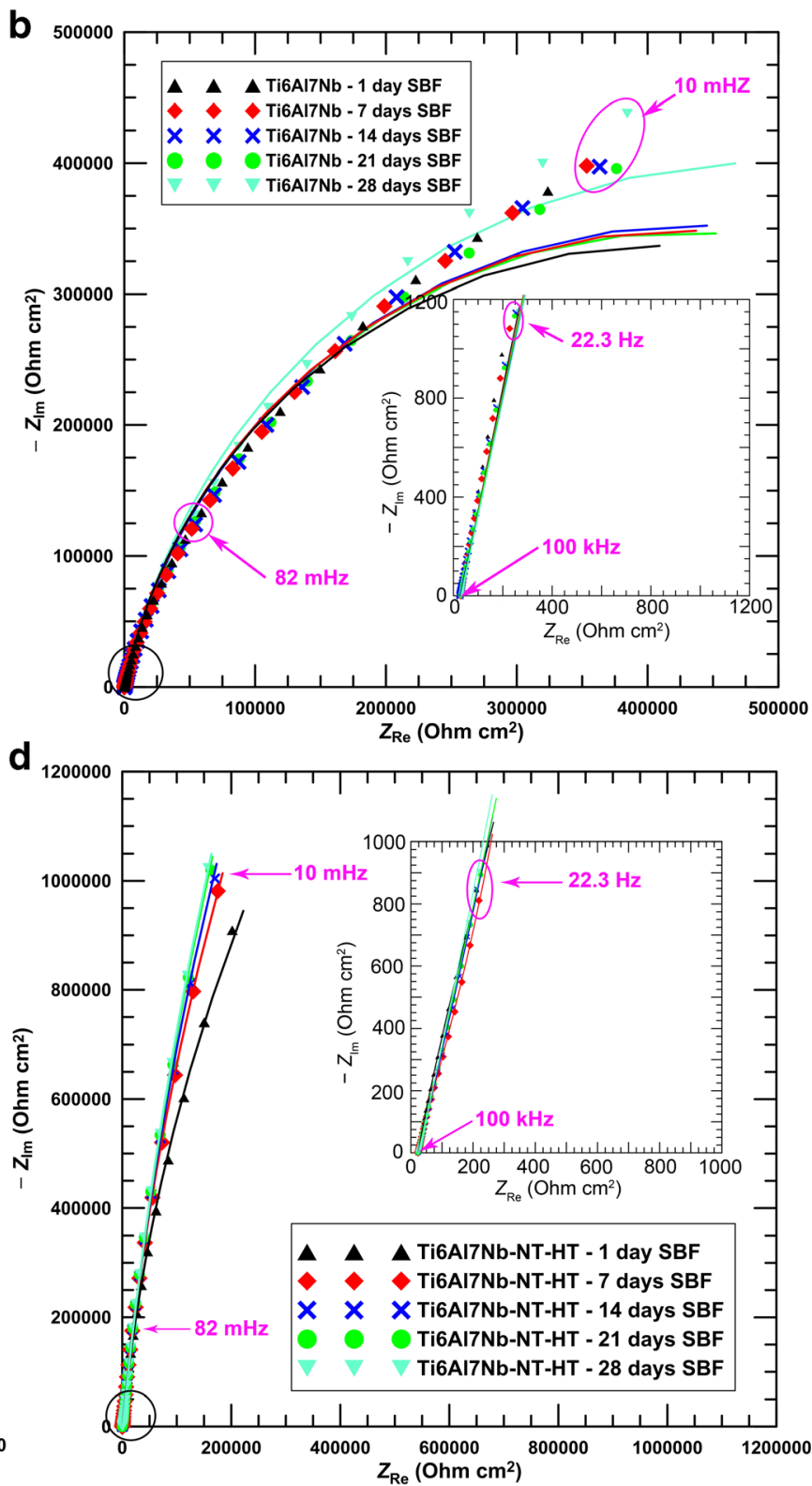

Fig. 9 Impedance diagrams representation (Nyquist) of examined surface during soaking in $\mathrm{SBF}$ solution for Ti (a), Ti6Al7Nb (b), Ti6Al7Nb-NT (c), and Ti6Al7Nb-NT-HT (d) 
Fig. 10 Equivalent circuits representing the impedance results for compact oxide layer and nanotube oxide layer a

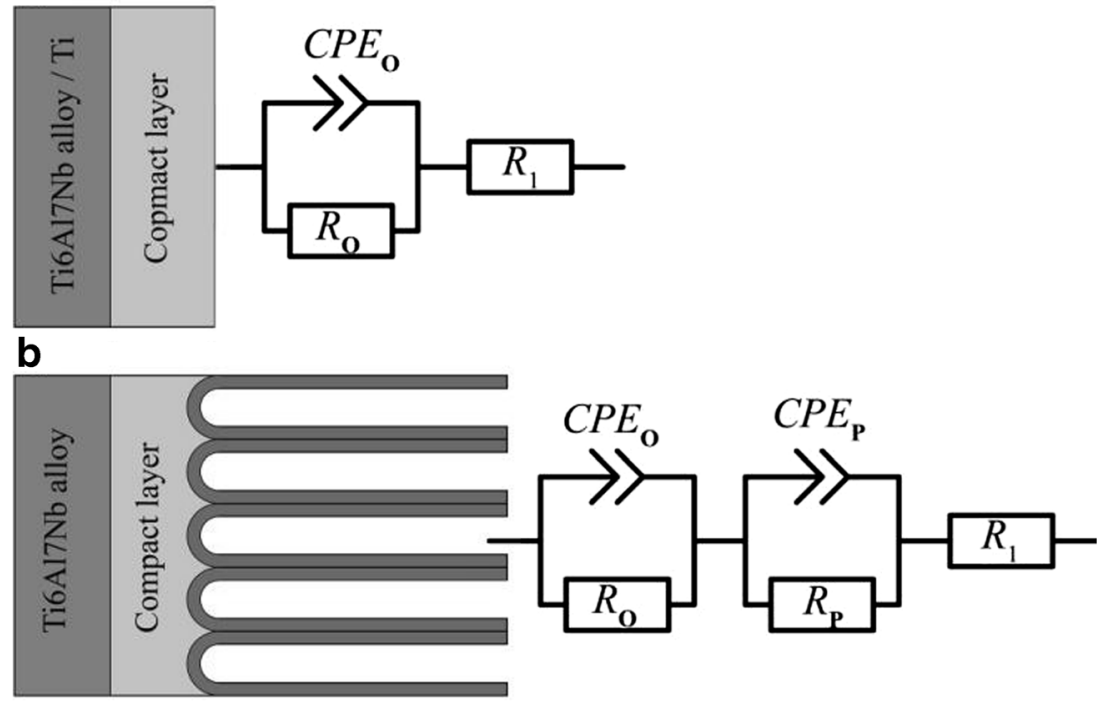

Nanotubes layer

treatment process of anodized Ti6Al7Nb sample was carried out at $200^{\circ} \mathrm{C}$ in air. This temperature is sufficient to produce an additional oxide barrier at the metal/oxide interface. The overall effect of $\mathrm{F}^{-}$removal and oxide formation is reflected in corrosion behavior of the oxide nanotubes. The obtained result of corrosion current measurements for Ti6Al7Nb samples show a decrease from $967 \mathrm{nA} / \mathrm{cm}^{2}$ to the level below $40 \mathrm{nA} / \mathrm{cm}^{2}$ after heat treatment. Thus, the alloy covered with oxide nanotubes exhibits the best corrosion resistance after heat treatment.

\section{EIS measurements}

In order to get deeper insight into the passivation phenomena at the electrode/electrolyte interface, and to follow the spontaneous apatite formation, electrochemical impedance spectroscopy (EIS) was used. In our study, impedance measurements were carried out under the conditions which are described in the experimental part. The results of impedance studies obtained after $24 \mathrm{~h}, 7,14$,

Table 2 Parameters obtained from impedance data by non-linear least-squares fits

\begin{tabular}{|c|c|c|c|c|c|c|c|c|}
\hline Soaking and measurements in SBF (day) & $R_{1}(\Omega)$ & $R_{\mathrm{p}}\left(\Omega \mathrm{cm}^{2}\right)$ & $\alpha_{\mathrm{p}}$ & $Q_{\mathrm{p}}\left(\mu \mathrm{F} \mathrm{cm}{ }^{-2} \mathrm{~s}^{\alpha-1}\right)$ & $R_{\mathrm{O}}\left(\Omega \mathrm{cm}^{2}\right)$ & $\alpha_{\mathrm{o}}$ & $Q_{\mathrm{o}}\left(\mu \mathrm{F} \mathrm{cm} \mathrm{cm}^{-2} \mathrm{~s}^{\alpha-1}\right)$ & $\chi^{2} \cdot 10^{-3}$ \\
\hline \multicolumn{9}{|l|}{ Ti6Al7Nb bare alloy } \\
\hline 1 & 59.62 & - & - & - & 822,380 & 0.8737 & 13.7 & 6.72 \\
\hline 7 & 55.24 & - & - & - & 856,590 & 0.8694 & 12.6 & 6.11 \\
\hline 14 & 50.65 & - & - & - & 873,660 & 0.8641 & 12.2 & 5.08 \\
\hline 21 & 57.67 & - & - & - & 854,020 & 0.8687 & 12.1 & 5.03 \\
\hline 28 & 62.36 & - & - & - & 989,580 & 0.8665 & 11.9 & 3.70 \\
\hline \multicolumn{9}{|l|}{ Ti6Al7Nb with nanotubes } \\
\hline 1 & 47.38 & 42,616 & 0.8273 & 39.4 & 428,380 & 0.8381 & 129.2 & 3.83 \\
\hline 7 & 45.51 & 28,739 & 0.8371 & 28.0 & 301,120 & 0.8360 & 11.3 & 2.32 \\
\hline 14 & 45.88 & 28,539 & 0.8328 & 25.3 & 367,580 & 0.8181 & 94.5 & 2.92 \\
\hline 21 & 44.43 & 27,097 & 0.8413 & 24.5 & 459,950 & 0.7794 & 81.0 & 3.45 \\
\hline 28 & 47.20 & 24,936 & 0.8591 & 23.8 & 514,360 & 0.7506 & 71.4 & 4.06 \\
\hline \multicolumn{9}{|l|}{ Ti6Al7Nb with nanotubes after heat treatment } \\
\hline 1 & 44.75 & $7.1410^{6}$ & 0.9394 & 13.9 & 533 & 0.7969 & 79.9 & 0.11 \\
\hline 7 & 45.77 & $1.1910^{7}$ & 0.9411 & 13.2 & 283 & 0.7576 & 91.8 & 0.11 \\
\hline 14 & 46.58 & $1.4710^{7}$ & 0.9393 & 13.0 & 445 & 0.7159 & 131.2 & 0.23 \\
\hline 21 & 45.57 & $1.7810^{7}$ & 0.9393 & 12.9 & 704 & 0.7189 & 122.5 & 0.27 \\
\hline 28 & 45.57 & $1.8310^{7}$ & 0.9393 & 12.8 & 1163 & 0.6915 & 148.0 & 0.22 \\
\hline
\end{tabular}


Fig. 11 SEM image of Ti6Al7 Nb alloy covered with oxide nanotubes after heat treatment before (a) and after (b) exposure for 28 days to SBF

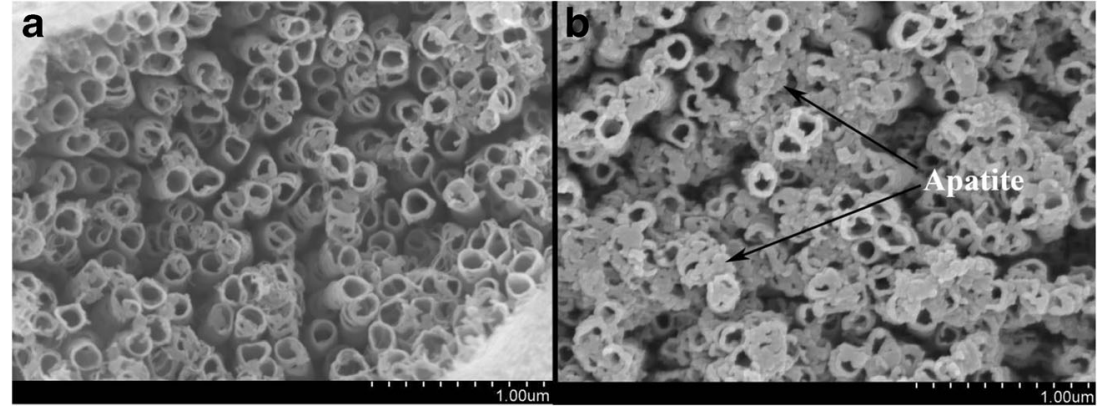

21 , and 28 days of soaking in SBF fluid are shown in Fig. 9a-d.

For the interpretation of the experimental data, we used equivalent circuits available in the literature [12, 35-37], which have been often applied to dense and porous oxide layer formed on the metal surface immersed in the electrolyte. Both models are based on Randles circuit and are shown in Fig. 10a, b. In both models, $R_{1}$ denotes the resistance of the electrolyte. In turn, $R_{\mathrm{O}}$ and $\mathrm{CPE}_{\mathrm{O}}$ denote polarization resistance and constant phase element, respectively, and describe the behavior of compact oxide layer, while $R_{\mathrm{P}}$ and $\mathrm{CPE}_{\mathrm{P}}$ are related to the behavior of porous layer of oxide nanotubes.

Constant phase element described by the equation:

$Z_{\mathrm{CPE}}=\frac{1}{(j \omega)^{\alpha} \cdot Q}$

enables to observe the changes of heterogeneity and porosity of the electrode. For $\alpha=1, Z_{\mathrm{CPE}}$ corresponds to the capacitor, for $\alpha=0$, it takes part of the resistor, and for $\alpha=-1$, it corresponds to the inductor [36, 38, 39].

In all the cases, the simplest equivalent circuits were chosen in order to achieve lower confidence intervals for the estimated parameters and to capture all qualitative features of the impedance spectra [35].

In the case of bare alloy, the results were fitted with model shown in Fig. 10a. It corresponds to metal covered with compact oxide layer. The model is similar to that one used in our previous study on corrosion resistance of Ti and Ti-Pd alloy in phosphate-buffered saline solution [12, 40]. Experimental data obtained for Ti6Al7Nb "bare" alloy are well described by the chosen circuit. It can be seen that as time flows, resistance is slightly increasing while capacity is insignificantly decreasing. It may suggest that on the electrode surface, apatite layer is not formed, and the observed change can be attributed to the slow growth of compact oxide layer.

In the case of the alloy covered with oxide nanotubes (without and after the heat treatment), for the interpretation of impedance data, the model shown in Fig. 10b was chosen. It incorporates two time constants which can be deducted from Bode plots. In both the cases, there is a decrease of $\alpha_{\mathrm{O}}$ which means deviation from pure capacitance due to surface inhomogenity [35]. It may be a result of apatite deposition on the surface of nanotubes. After heat treatment, nanotubes exhibit almost constant $\alpha_{\mathrm{P}}$ (which is close to that for pure capacitor) during the time of experiment (i.e., up to 28 days) with simultaneous increase of resistance. It may reflect the oxide growth due to annealing in air. Nanotubes without heat treatment show an increase of $\alpha_{P}$ and decrease of resistance with time of soaking. It may be a result of residual fluoride dissolution in the electrolyte.

The results interpreted in a way described above are gathered in Table 2. The chi square test indicates that the fit of model to the data is good $\left(10^{-3}-10^{-4}\right)$, which speaks for the applicability of both models. In order to verify the correctness of EIS measurements, for all the obtained spectra, the
Fig. 12 EDS and XPS spectra obtained for heat-treated nanotube layer after soaking experiments (28 days) a Atomic concentration (\%) \begin{tabular}{lllllllll}
$\mathrm{Ti}$ & $\mathrm{Al}$ & $\mathrm{Nb}$ & $\mathrm{Ca}$ & $\mathrm{P}$ & $\mathrm{O}$ & $\mathrm{Au}$ & $\mathrm{C}$ & $\mathrm{Na}$ \\
\hline
\end{tabular}

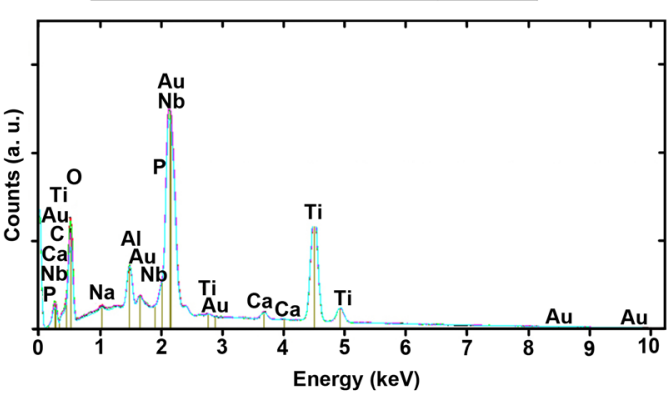

b Atomic concentration (\%)

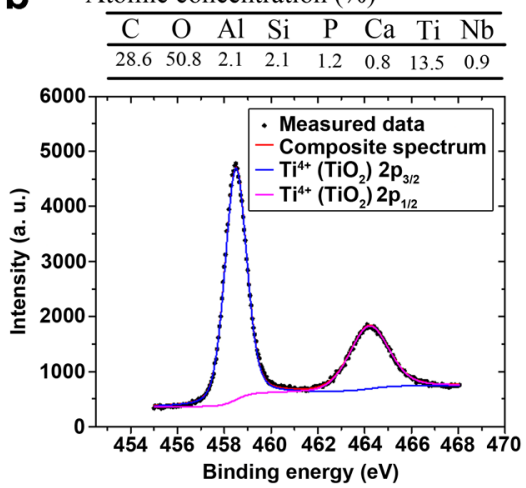


Kramer-Kronig test was performed. It consists in the transformation of real axis into the imaginary axis and the imaginary axis into the real axis. This procedure was recently used by Feng et al. [41] in the study of passivity of 316L stainless steel in borate buffer solution. Its detailed explanation is given in the book of Orazem and Tribolet [38] and by Macdonald [42]. For all the measurements, the test result ranged from $10^{-5}$ to $10^{-6}$, and it means that EIS measurements were performed very well. It is also clear from EIS results that the best corrosion resistance exhibits Ti6Al7Nb alloy covered with oxide nanotubes after heat treatment. The results are in good agreement with the results of polarization studies.

Soaking experiments performed with the alloy covered with oxide nanotubes after heat treatment took 28 days. The comparison of the oxide surface before and after soaking experiments is shown in Fig. 11a, b. EDS and XPS (Fig. 12a, b) analysis showed after experiments that apatite is formed on the nanotube surface. This oxide nanotube layer was synthesized at the voltage of $30 \mathrm{~V}$.

It is seen that apatite has grown on the top of nanotubes. We have no evidence that its penetration inside nanotubes occurred. The similar result was obtained for Ti6Al7 $\mathrm{Nb}$ alloy covered with oxide nanotubes without any heat treatment. In the case of pure Ti and bare alloy, we observed that the apatite deposition did not occur. It means that for the deposition of apatite, porous oxide is needed.

\section{Conclusions}

In the present study, the conditions of oxide nanotube formation on Ti6 $\mathrm{Al} 7 \mathrm{Nb}$ were investigated. It was found that, similarly to $\mathrm{ZrO}_{2}$ nanotubes, the size of nanotubes is a linear function of applied potential, and in the range of potentials from 10 to $35 \mathrm{~V}$, the inner diameter can vary from 30 to $110 \mathrm{~nm}$.

Corrosion resistance study conducted by polarization and EIS measurements gave similar results. Electrochemical measurements were performed on the samples anodized at constant voltage of $30 \mathrm{~V}$. Polarization tests revealed that an alloy covered with oxide nanotubes subjected to the heat treatment exhibits the best corrosion resistance. EIS results were interpreted with two models based on Randles' circuit. These experiments also showed that an alloy covered with oxide nanotubes after heat treatment exhibits the best corrosion resistance, which polarization studies confirmed. The deposition of apatite on investigated samples occurred only on alloy samples after anodization, with and without heat treatment. Formation of the apatite and corrosion studies indicates that the alloy covered with oxide nanotubes formed under potential of $30 \mathrm{~V}$ after heat treatment is well suited for biological integration.
Acknowledgments This work had financial support from the Polish Ministry of Science and Higher Education with the grant no. 15.11.180.172.

Open Access This article is distributed under the terms of the Creative Commons Attribution 4.0 International License (http:// creativecommons.org/licenses/by/4.0/), which permits unrestricted use, distribution, and reproduction in any medium, provided you give appropriate credit to the original author(s) and the source, provide a link to the Creative Commons license, and indicate if changes were made.

\section{References}

1. Breme HJ, Helsen JA, Biehl V, Humbeeck JV, Stalmans R, Besselink PA, Worch H, Possart W, Barbosa MA, Rocha LA, Hildebrand HF, Hornez JC, Thull R, Jones DB, Hartmann U, Hubrecht J, Laffargue P (1998) Metals as biomaterials. John Wiley \& Sons Ltd., Chichester

2. Black J (2005) Biological performance of materials: fundamentals of biocompatibity. CRC Press, London

3. Scully JR (2000) Corrosion of titanium alloys. Electrochem Soc Proc: $187-201$

4. Solar RJ, Pollack SR, Korostoff E (1979) In: Syrett BC, Acharya A (ed) Corrosion and degradation of implant materials, American Society for Testing and Materials, Baltimore

5. Geetha M, Singh AK, Asokamani R, Gogia AK (2009) Ti based biomaterials, the ultime choice for orthopedic implants - a review. Prog Mater Sci 54:397-425

6. Assis SL, Costa I (2007) Electrochemical evaluation of Ti-13Nb13Zr, Ti-6Al-4V and Ti-6Al-7Nb alloys for biomedical application by long-term immersion test. Mater Corros 58:329-333

7. Popa MV, Raducanu D, Vasilescu E, Drob P, Cojocaru D, Vasilescu C, Ivanescu S, Rosca JCM (2008) Mechanical and corrosion behaviour of a Ti-Al-Nb alloy after deformation at elevated temperatures. Mater Corros 59:919-928

8. Robin A, Carvalho OAS, Schneider SG, Schneider S (2008) Corrosion behavior of Ti-xNb-13Zr alloys in Ringer's solution. Mater Corros 59:929-933

9. Al-Mobarak NA, Al-Swayih AA, Al-Rashoud FA (2011) Corrosion behavior of Ti-6Al-7Nb alloy in biological solution for dentistry applications. Int J Electrochem Sci 6:20312042

10. Cvijovic-Alagic I, Cvijovic Z, Mitrovic S, Panic V, Rakin M (2011) Wear and corrosion behaviour of Ti-13Nb-13Zr and Ti-6Al-4V alloys in simulated physiological solution. Corros Sci 53:796-808

11. Simka W, Mosiałek N, Nawrat G, Nowak P, Żak J, Szade J, Winiarski A, Maciej A, Szyk-Warszyńska L (2012) Electrochemical polishing of Ti-13Nb-13Zr alloy. Surf Coat Technol 213:239-246

12. Handzlik P, Fitzner K (2013) Corrosion resistance of Ti and Ti-Pd alloy in phosphate buffered saline solutions with and without $\mathrm{H}_{2} \mathrm{O}_{2}$ addition. T Nonferr Metal Soc 23:866-875

13. Kokubo T, Takadama H (2006) How useful is SBF in predicting in vivo bone bioactivity? Biomaterials 27:2907-2915

14. Wilmowski C, Bauer S, Lutz R, Meisel M, Neukam FW, Toyoshima T, Schmuki P, Nkenke E, Schlegel KA (2009) In vivo evaluation of anodic $\mathrm{TiO}_{2}$ nanotubes: an experimental study in the pig. J Biomed Mater Res B 89B:165-171

15. Narayanan R, Lee H-J, Kwon T-Y, Kim K-H (2011) Anodic $\mathrm{TiO}_{2}$ nanotubes from stirred bath: hydroxyapatite growth \& osteoblast responses. Mater Chem Phys 125:510-517 
16. Tsuchiya H, Berger S, Macak JM, Ghicov A, Schmuki P (2007) Self-organized porous and tubular oxide layers on TiAl alloys. Electrochem Commun 9:2397-2402

17. Mohseni E, Zalnezhad E, Bushroa AR (2014) Comparative investigation on the adhesion of hydroxyapatite coating on Ti-6Al-4V implant: a review paper. Int J Adhes Adhes 48:238-257

18. Macak JM, Tsuchiya H, Taveira L, Ghicov A, Schmuki P (2005) Self-organized nanotubular oxide layers on Ti-6Al-7Nb and Ti$6 \mathrm{Al}-4 \mathrm{~V}$ formed by anodization in $\mathrm{NH}_{4} \mathrm{~F}$ solutions. J Biomed Mater Res A 75A:928-933

19. Stępień M, Handzlik P, Fitzner K (2014) Synthesis of $\mathrm{ZrO}_{2}$ nanotubes in inorganic and organic electrolytes by anodic oxidation of zirconium. J Solid State Electrochem 18:3081-3090

20. Sittig C, Haner G, Marti A, Textor M, Spencer ND (1999) The implant material, Ti6Al7Nb: surface microstructure, composition and properties. J Mater Sci Mater Med 10:191-198

21. Andersson JO, Helander T, Höglund L, Shi PF, Sundman B (2002) Thermo-Calc and DICTRA, Computational tools for materials science. Calphad 26:273-312

22. Witusiewicz VT, Bondar AA, Hecht U, Velikanova TY (2009) The Al-B-Nb-Ti system IV. Experimental study and thermodynamic reevaluation of the binary Al-Nb and ternary Al-Nb-Ti systems. J Alloys Compd 472:133-161

23. Macak JM, Tsuchiya H, Ghicov A, Yasuda K, Hahn R, Bauer S (2007) Schmuki P (2007) TiO2 nanotubes: self-organized electrochemical formation, properties and applications. Curr Opin Solid St M 11:3-18

24. Crawford GA, Chawla N, Das K, Bose S, Bandyopadhyay A (2007) Microstructure and deformation behavior of biocompatible $\mathrm{TiO}_{2}$ nanotubes on titanium substrate. Acta Biomater 3:359-367

25. Roy P, Berger $\mathrm{S}$, Schmuki $\mathrm{P}(2011) \mathrm{TiO}_{2}$ nanotubes: synthesis and applications. Angew Chem Int Ed 50:2904-2939

26. Rafieerad AR, Zalnezhad E, Bushroa AR, Hamouda AMS, Sarraf M, Nasiri-Tabrizi B (2015) Self-organized TiO2 nanotube layer on Ti-6Al-7Nb for biomedical application. Surf Coat Technol 265: 24-31

27. Habazaki H, Fushimi K, Shimizu K, Skeldon P, Thompson GE (2007) Fast migration of fluoride ions in growing anodic titanium oxide. Electrochem Commun 9:1222-1227

28. Garcia-Vergara SJ, Skeldon P, Thompson GE, Habazaki H (2006) A flow model of porous anodic film growth on aluminium. Electrochim Acta 52:681-687

29. Biesinger MC, Lau LWM, Gerson AR, Smart RSC (2010) Resolving surface chemical states in XPS analysis of first row transition metals, oxides and hydroxides: $\mathrm{Sc}, \mathrm{Ti}, \mathrm{V}, \mathrm{Cu}$ and $\mathrm{Zn}$. Appl Surf Sci 257:887-898

30. Tsuchiya H, Macak JM, Taveira L, Schmuki P (2005) Fabrication and characterization of smooth high aspect ratio zirconia nanotubes. Chem Phys Lett 410:188-191

31. Ghicov A, Aldabergenova S, Tsuchyia H, Schmuki P (2006) $\mathrm{TiO}_{2-}$ $\mathrm{Nb}_{2} \mathrm{O}_{5}$ nanotubes with electrochemically tunable morphologies. Angew Chem Int Ed Eng 45:6993-6996

32. Wang L-N, Luo J-L (2012) Electrochemical behaviour of anodic zirconium oxide nanotubes in simulated body fluid. Appl Surf Sci 258:4830-4833

33. Fang D, Yu J, Luo Z, Liu S, Huang K, Xu W (2012) Fabrication parameter-dependent morphologies of self-organized $\mathrm{ZrO}_{2}$ nanotubes during anodization. J Solid State Electrochem 16:1219-1228

34. Vacandio F, Eyraud M, Knauth P, Djenizian T (2011) Tunable electrical properties of self-organized zirconia nanotubes. Electrochem Commun 13:1060-1062

35. Bozzini B, Carlino P, Mele C (2011) Electrochemical behaviour and surface characterisation of $\mathrm{Zr}$ exposed to an SBF solution containig glycine, in view of dental implant applications. J Mater Sci Mater Med 22:193-200

36. Benea L, Mardare-Danaila E, Mardare M, Celis J-P (2015) Preparation of titanium oxide and hydroxyapatite on Ti-6Al-4V alloy surface and electrochemical behaviour in bio-simulated fluid solution. Corros Sci 80:331-338

37. Kanta A-F, Poelman M, Decroly A (2015) Electrochemical characterisation of $\mathrm{TiO}_{2}$ nanotube array photoanodes for dye-sensitized solar cell application. Sol Energy Mater Sol Cells 133:76-81

38. Orazem ME, Tribollet B (2008) Electrochemical impedance spectroscopy. John Wiley \& Sons, Hoboken, New Jersey

39. Hirschorn B, Orazem ME, Tribollet B, Vivier V, Frateur I, Musiani M (2010) Constant-phase-element behavior caused by resistivity distribution in films. J Electrochem Soc 157:C452-C457

40. Handzlik P, Fitzner K (2007) Electronic properties of anodic oxide films on titanium in phosphate buffered saline solution and artificial salivia determined by EIS method. Arch Metall Mater 52:543-553

41. Feng Z, Cheng X, Dong C, Xu L, Li X (2010) Passivity of 316L stainless steel in borate buffer solution studied by Mott-Schottky analysis, atomic absorption spectrometry and X-ray photoelectron spectroscopy. Corros Sci 52:3646-3653

42. Urquidi-Macdonald M, Real S, Macdonald DD (1990) Applications of Kramers-Kronig transforms in the analysis of electrochemical impedance data-III. Stability and linearity. Electrochim Acta 35:1559-1566 